\title{
ARCHITECTURAL ANALYSIS OF THERAPEUTIC CANTERS FOR DRUG ADDICTS
}

\author{
DOI: 10.18485/arh_pt.2020.7.ch50
}

\author{
- Sadoud Nesma \\ PhD Student, Architecture, University of Pécs, Faculty of Engineering and \\ Information Technology, Breuer Marcel Doctoral School, amsen.archi@gmail.com

\section{_ Erzsébet Szeréna Zoltán} \\ University of Pécs, Faculty of Engineering and Information Technology, \\ Institute of Architecture, 7624 Pécs, Boszorkány u.2. betty.zoltan@mik.pte.hu
}

\section{ABSTRACT}

The design of healthcare buildings is questioned in several types of research, and it's still studying from different sides, this research aims to target the rehab canters and their relations with patients. moreover, it's interested in finding the interaction that occurs between the spatial quality of rehab centers and the well-being of addicted patients based on the visual perception concept. It requires therefore, an understanding of which factors can contribute to the physical qualities of the spaces, and it studies the architectural characters of establishments.

To achieve this research, an inductive approach is adopted rest on identifying and testing the variables and factors associated with the assessment of physical space and its impact on the user's perception of construction, which are subdivided into three proposed factors; (the functional, spatial, and historical factors).

KEYWORDS _ design, healthcare, well-being, spatial quality, visual perception

\section{INTRODUCTION}

The aim of this research was to determine the visual perception of patients suffer the dependence on drugs in their healthcare spaces, thus the issue is related with the hypothesis that spatial quality of this sensitive institutions had a certain role or impact that can be direct or indirect on the patients' behavior. This paper suggests classifying, decreasing, and representing the data in a term of manful themes to create a lead for this research. (DEVLIN, 2002)

The quality of the architectural space is connected by several parameters that can have an influence on the perception of this space which figures several functionalities in the quotidian of the users, many studies focus on how the environment can provide wellness for the individual and how sensitive design effects the recovery of patients, but some research remains still vague in identifying some relationships.

To carry out this study a comparative evaluation was opted for which the spatial quality is focused, and this study takes its criteria from the visual perception of an architectural space and its influence on the behavior of the occupant, this concept of perception interposes the relationships between the perception of elements and their interpretation.

As architecture gives space its physical shape, architects and psychologists seek to link the architecture and the psychology of the users into the physical space. The perception process is the first 
stage to interact with space; for this purpose, the architectural studies define this concept first by; Creating space and being perceived by users, then distinguishing it to identify its characteristics and its functioning. (POP, 2013) (P, 2009)

This article is a prelude to organizing the stages and steps of research to identify what the perception is and how this process controls the correlation with space and patients.

The study cases on which this study will be conducted have been chosen in Algeria, the choice fell on three institutions that agreed to take part in this report and they share the same point of treating drug addicts, after interviewing the employees in each institution, it was noticed that they follow the same method and stages of treatment, which helps this research to attribute its analysis much more in the architectural side.

\section{INTRODUCTION OF CASE STUDIES}

To start this research three establishment are selected from Algeria as it mentioned below, and to keep the study scientific without any nomination, this establishment will be kept anonym with coding: the first institute (E01), the second institute (E02) and the third one (E03). (Nesma, 2019)

1 The institute (E01):

This establishment is located in city in the north part of the country, with a capacity of 30 beds 15 women and 15 men. The hospitalization of drug addicts can take from 21 days to 6 weeks until the patient becomes stable; Then he follows the external treatment until the complete healin
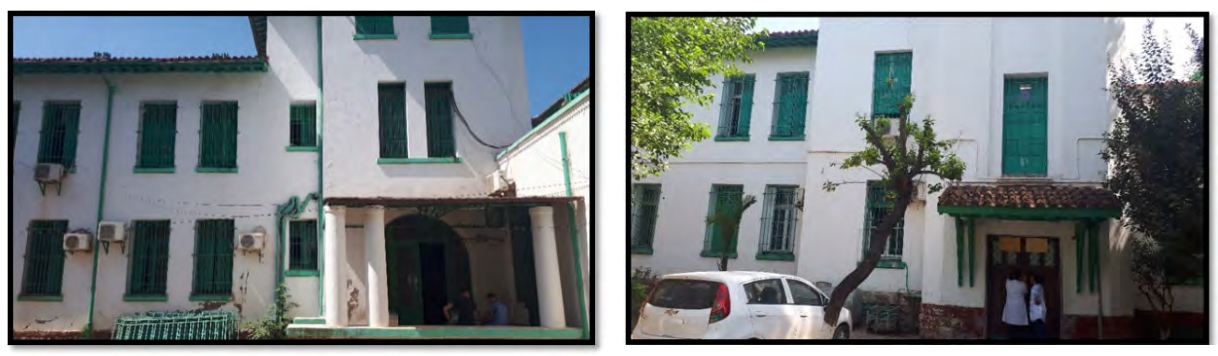

_ Figure 1: An external photo of the first center (E01). Source: Author.

2 The institute (E02):

The establishment is located in city in the northwest of Algeria; It hosts currently 25 patients (men) shared between drug addicts and people with mental disorders. Hospitalization of drug addicts can take 21 days or more until the patient becomes more stable and then fate for external hospitalization until complete healing.

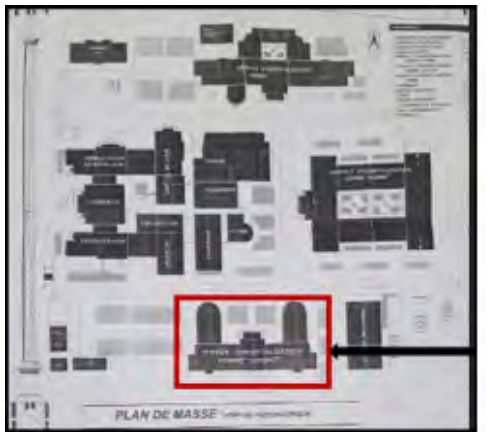

block for hospitalization (men)

_ Figure 2: the second institute situation (E02). Source: Author 
3. The institute (E03):

This establishment located in the capital Algiers, unlike the previous institutions this establishment is a day-care center, it follows the same care method and treatment units except that it does not provide accommodation space for patients. The choice of criteria in this research is opted for the purpose of touching the elements contributing to influence the visual perception of patients within these institutions.
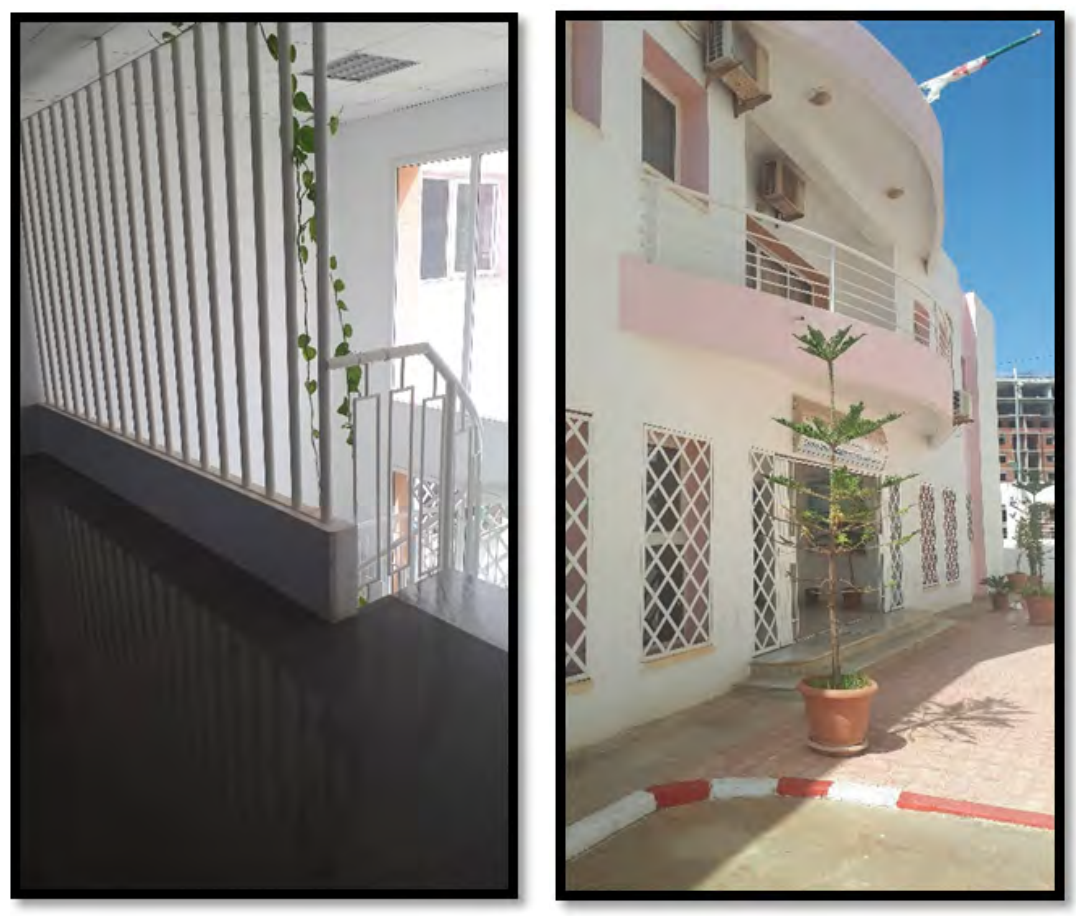

_ Figure 3: Photos about the third center (E03). Source: Author.

\section{THE METHODOLOGY:}

The centers selected above participate in adopting the same stages of medical treatment, but they differ in terms of available services, architecture, geographical and historical background for each building. These factors were chosen in the comparative study because the architectural aspect is not sufficient to judge the quality of the place and the flow of patients who arrive there. As well as the effectiveness of the treatment, in the architectural field, these factors can be summarized for that the gaps can be compared to ultimately determine the most efficient building to complete study and extract the appropriate wills to build this type in the future.

a) The historical scope:

This scope investigates the historical aspect of the therapeutic centers to determine the identity of building and the impacts of this factor on their performance by addressing:

the urban context of the project "urban reading": the elements of the context present an important role in understanding spatial planning because often these components are a product of the urban history, of the structure of which fits the analyzed project. (Evans, 1984)

The Urban reading enables the analysis of the surrounding buildings and their impact on the perception of selected institutions.

The historical background of the building may affect its physical quality. The cases selected in this 
research vary from institutions specifically designed to treat addicts while others were created for another activity and then changed their functionality and underwent rehabilitation. This should be decided by interviewing the staff of the centers. (Estelle, 2014)

b) The functional scope:

The spatial system contains multiple functions in relation. The method followed in this study heading towards the determination and classification of the relevant places according to their functioning and the activities carried out within the establishment, with the purpose to describe the samples' characteristics, and getting the information concerning the existing installations and thus identifying the model of care in each establishment. (CHING, 2007) (Estelle, 2014)

Moreover, this method contributes the determination of the functional character of the places to note the daily occupation and the frequentation of the space by the patients, this is connected by the concept space-time which represents the key moments of a typical day of an addicted patient in a rehab center.

The spatial configuration and the living pattern within these treatment centers are the two reference points for how the different functions are specialized in different ways and giving a conductor wire for evaluation and spatial design based on this deep structure.

The classification is based on including the functional contents of the different facilities in the establishments under common concepts to understand the functional structure of the place:

- The treatment spaces: these spaces are for the psychological consultation and medical examination, stimulation sessions, etc. These treatments are part of patients' day routine.

- Spaces for activities: these places are connected to the treatment spaces because they work on the motor and mental stimulation through various activities

_ Rest areas (bedrooms): these spaces are a very important part in the time of hospitalized patients.

_ Free time spaces: in these areas the patients are freer in their activities, they can play, relax and socialize.

_ Waiting areas: the waiting room is an important area especially for drug addicts who are following their out-patient treatment (non-hospitalized), and it is possible that even these places affect the behavior of patients. According to a previous study focuses on the perception of the waiting area and proves its ability to directly and indirectly influence the quality of care thanks to its architectural quality, design, lighting, furniture, etc. (DEVLIN, 2002)

_ Table 1: a table classifies the functions of each institution according to their mainly roles.

\begin{tabular}{|c|c|c|c|}
\hline & E01 & E02 & E03 \\
\hline The waiting area & provided & provided & provided \\
\hline The treatment spaces & $\begin{array}{l}\text {-Psychologist offices } \\
\text {-Psychiatrist } \\
\text {-Rehabilitation room }\end{array}$ & $\begin{array}{l}\text {-Psychologist offices } \\
\text {-Psychiatrist offices }\end{array}$ & $\begin{array}{l}\text {-Psychologist offices } \\
\text {-Psychiatrist offices } \\
\text {-Social assistant office } \\
\text {-Rehabilitation room } \\
\text {-Sample room }\end{array}$ \\
\hline Spaces for activities & $\begin{array}{l}\text {-Ergo therapy room (the } \\
\text { activities are carried out } \\
\text { in the ergo therapy } \\
\text { room) }\end{array}$ & $\begin{array}{l}\text {-Ergo therapy room } \\
\text {-Play area } \\
\text {-The kitchen } \\
\text {-Computer room }\end{array}$ & $\begin{array}{l}\text {-Ergo therapy room } \\
\text {-Computer room } \\
\text {-Sports room }\end{array}$ \\
\hline Free time spaces & $\begin{array}{l}\text {-The courtyard } \\
\text {-The TV room } \\
\text {-The play area }\end{array}$ & $\begin{array}{l}\text {-The courtyard } \\
\text {-The TV room }\end{array}$ & -Not provided \\
\hline The rest area & -Individual bedrooms & $\begin{array}{l}\text {-Isolation room } \\
\text {-Bedrooms for group }\end{array}$ & -Not provided \\
\hline
\end{tabular}




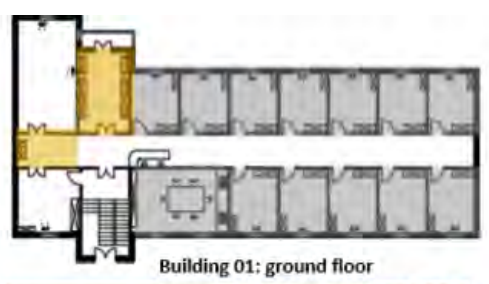

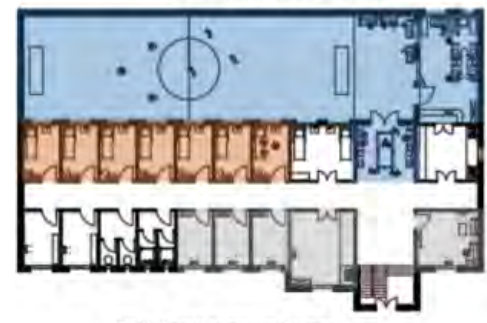

Building 02: ground floor
Waiting area

The treatment spaces

Spaces for activities

Free time spaces

Rest area

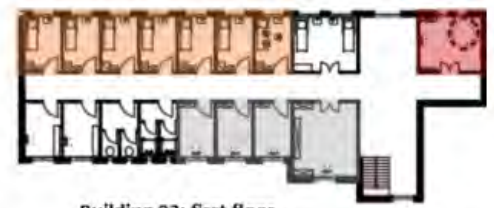

Building 02: first floor

_ Figure 4: the functional classification of the first institute (E01). Source: author

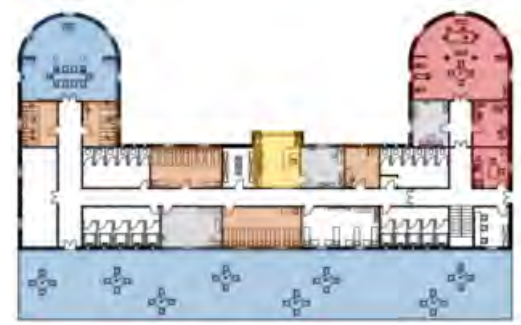

Waiting area
The treatment spaces

Spaces for activities

Free time spaces

Rest area

_ Figure 5: The functional classification of the second institute (E02). Source author
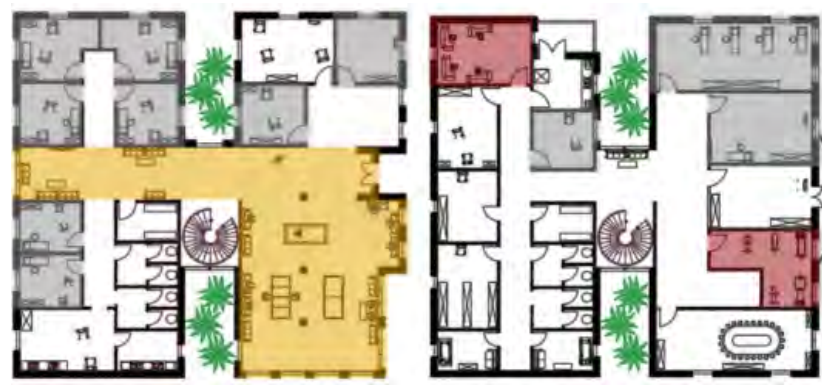

Waiting area

The treatment spaces

Spaces for activities

_ Figure 6: The functional classification of the third institute. Source author

c) The spatial scope:

The therapeutic environment includes several interrelated features in both terms of the physical environment and health conditions. The area of focus in the study is about the physical environment within the therapeutic centers, by using a combined method evaluation of clinical behavior of patients and the spatial design under the main priority which is the impact of physical design on patient behavior. (Daniel Oberfeld, 2011) (BINGGELI, 2005) (CHING, 2007)

It's obvious that the physical facilities are determined by different therapy faiths, besides, the physical elements of the interior space have an influence on the way the visual perception of the environ- 
ment could be, consequently the behavior of users.

The evaluation method is based on a component (qualitative/observational), by involved screening all elements that identify the physical space:

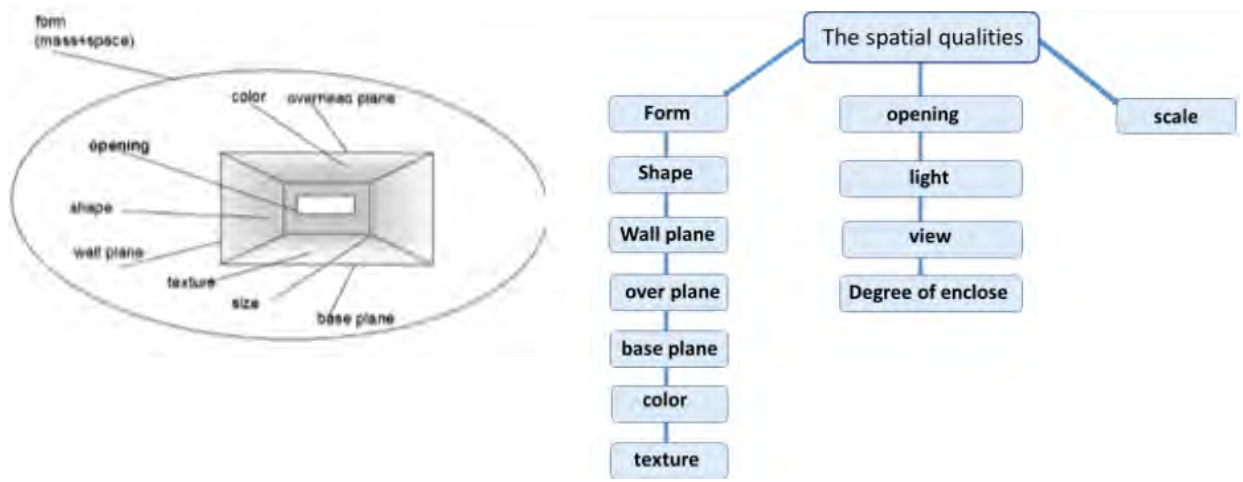

_ Figure 8 (left): The spatial components that effect the visual perception. Source: (Nesma, 2019) _ Figure 9 (right): The elements of spatial quality. Source: Author

\section{DISCUSSION AND RESULTS}

The historical scope analyses: The article suggests that the socio-geographical and historical aspects of each institution can influence the flow of patients to these institutions and their perceptions. As well as provide the study with information about the changes that have occurred in each building.

Regarding the establishment of (E01), it is an ancient center dating back to the French era in Algeria, where it is located within a group of other buildings that provide multiple medical services. This building has undergone functional and spatial alterations and is considered the most heavily controlled by patients, perhaps due to its historical background and even social geography.

Both the establishment (E02) (E03); are new construction compared to the first center, the establishment (E02); is dedicated as psychiatry, but it receives drug addict patients for hospitalization. According to the interviews with doctors, this can be an influencer factor for decreasing patients flow, even the progression of treatment.

The functional scope analyses: To be able to evaluate the establishment at the functional level, the paper opted to unify the relevant places and spaces that share the same activities. This method makes it possible to notice the gaps in each establishment (Table 01) and making the selection of optimal establishment for further research logical.

The spatial scope analyses: This stage made it possible to identify, analyze, and relate the internal elements of the building to the behavior of patients. The results of the spatial component analysis assume that the interior quality of the building affects the behavior of patients and their frequentation at each space. (Nesma, 2019)

\section{CONCLUSION}

The processes selected in such a way as to organize the structure of the research and in parallel it makes it possible to represent the quality of each establishment and its influence on the visual perception of the addicts who undergo a sensitive situation during this period of dependence, this hypothesis includes the purpose of the research that remains to prove or to be denied in the next relative studies. 


\section{REFERENCES}

- BINGGELI FRANCIS D.K. CHING . CORKY INTERIOR DESIGN ILLUSTRATED [Book]. - New Jersey : John Wiley \& Sons, Inc., 2005.

- CHING FRANCIS D.K. architecture architecture FORM, SP A CE, AND ORDER. third edition [Book]. - New Jersey : @ 2007 by John Wiley \& Sons, Inc. , 2007.

- Daniel Oberfeld Heiko Hecht "Fashion versus perception: The impact of surface lightness on the perceived dimensions of interior space [Journal]. - [s.I.] : sagepublications, 2011. - 284-398.

_ DEVLIN ALLISON B. ARNEILL AND ANN SLOAN PERCEIVED QUALITY OF CARE: THE INFLUENCE OF THEWAITING ROOM ENVIRONMENT [Journal]. - London : Elsevier Science, 2002. - 345-360 : Vol. 22. - 2. _ Estelle DEMILLY AUTISM AND ARCHITECTURE, in french (AUTISME ET ARCHITECTURE,Relations entre les formes architecturales et l'état clinique des patients) [Book]. - Lyon : Doctoral thesis : National School of Architecture of Lyon Discipline: Architecture, 2014.

- Evans Gary W. Environmental Stress [Conference]. - London : Combridge university press, 1984.

- Nesma Sadoud THE RELATIONSHIP BETWEEN SPACE QUALITY OF ADDICTION CENTRES AND PATIENT BEHAVIOUR [Journal]. - Pecs,Hongary : 6th INTERNATIONAL ACADEMIC CONFERENCE ON PLACES AND TECHNOLOGIES., 2019.

- P Silverstein Steven M. Keane Brian Perceptual organization in schizophrenia: Plasticity and state-related change [Journal]. - [s.I.] : Pollack Periodica, 2009. - 2 : Vol. 1. - DOI 10.1556/LP.1.2009.2.111.

_ POP Dana Space Perception and Its Implication in Architectural Design [Journal]. - Cluj-Napoca, Romania : Acta Technica Napocensis: Civil Engineering \& Architecture , 2013. - 2 : Vol. 56. 